\title{
Anger and the Politics of Naming
}

As interworked systems of construable signs ..., culture is not a power, something to which social events, behaviors, institutions, or processes can be causally attributed; it is a context, something within which they can be intelligibly described.

-Clifford Geertz, The Interpretation of Cultures

To discover what we are feeling (our emotions) is not necessarily or usually to discover some new feelings (pang, frisson, wave, or whatever); rather, it is to discover what all of that means, how it fits in with who we are and what we are up to. It is to put a name to a mass of rather disparate stuff, to situate the otherwise inchoate "inner" in a social world, to join (introspectible) feeling and behavior in a significant way, to note a meaningful pattern.

The ways we have for doing this, our vocabulary of the emotions, are given socially: the patterns to be found are various but not infinite and not wholly in our individual power to change. Societies categorize at least some of the emotions in at least slightly different ways. They find different conjunctions of feeling and behavior significant, and the significance can change over time. ${ }^{1}$

On an individual level poetry and novels can change the ways we read ourselves -not just tell us we have been in love, but enable us to be by showing us what

The long history of this paper has implicated, beyond my ability to disentangle their contributions, many members of the Canadian and American Societies for Women in Philosophy and the Canadian Research Institute for the Advancement of Women. I am grateful for the criticism, the ideas, the support, and the entanglement. Burton Dreben and David Hills were particularly helpful with the penultimate version, which appeared in my doctoral dissertation "Depsychologizing Psychology: Essays against Individualism in the Philosophy of Mind" (Harvard, 1978). Sally McConnell-Ginet was an encouraging and insightful editor, particularly when it came to recasting the essay in a more intelligible form. The preparation for the final version was managed, with the most tactful bullying, by Eta Schneiderman, to whose stylistic sensibilities and clearheadedness this paper owes whatever clarity it may have.

${ }^{1}$ See Denis DeRougemont, Love in the Western World (New York, N.Y.: Pantheon, 1956). Also Virginia Woolf, Night and Day (New York, N.Y.: Harcourt Brace Jovanovitch, 1948), for a discussion of whether intense and obsessive feelings are to count as love for two sensible, "modern" people. 
power, ses can can be ultures y or usually ather, it is to what we are he otherwise behavior in

$\mathrm{s}$, are given t wholly in he emotions feeling and

id ourselves ing us what

ntangle their r Women in 'omen. I am Dreben and reared in my talism in the uraging and : intelligible ul bullying, paper owes

: Pantheon, ovanovitch, as love for

it would mean for that to be love (perhaps homosexual love, or nonspectacular, quiet attachment). ${ }^{2}$ This enabling is not just freeing us to feel in the future but, equally important, showing us how to read the past. In addition, changes can be seen as political and ideological. As we change our beliefs and opinions about, for instance, the existence and nature of sexual oppression, we can come to change the ways in which we interpret our own feelings and behavior.

In this paper I will examine three different sorts of changes that can occur in the case of anger. One is becoming angry, the second is discovering that one has been angry, and the third is changing what counts as being angry. While the first is (philosophically) uncontroversial, the second and (especially) the third pose difficulties for the traditional picture of mind and language, a picture that stands opposed to the view I have just outlined. After sketching the traditional picture, I will elaborate the alternative model as a way of giving a better account of what we are learning through the practices of the women's movement, in particular, through the experiences of the creation and the discovery of anger in consciousness-raising groups.

\section{The Traditional Picture}

The traditional picture of mind comes from Descartes: on the surface of the stream of consciousness float leaves that are our sensations, thoughts, and feelings, each unmistakably labeled. ${ }^{3}$

Freud has modified this picture: not all the leaves float on the surface. Some leaves, by the force of the directional flow of the stream (the ego), have been thrust to the bottom and covered with silt (repression). Because they are there, they disturb in gross or subtle ways the flow of water over them and thus the behavior of the leaves still on the surface (neuroses, parapraxes, dreams, and so on). In order to free the leaves and hence free ourselves from the disturbances they cause while hidden, we need to uncover them. We can do this by interpreting the clues we gather from the eddies and whirlpools they create (psychoanalysis).

The heart of the traditional picture is this: when we talk about the emotions, conscious or unconscious, we are talking about some particular mental or physical state that is "in" us (or that we are in) that makes what we are saying true. The anger, the joy, the love, the grief are supposed to have been there all along, awaiting discovery and naming. It is this picture I want to argue against through

\footnotetext{
${ }^{2}$ In his portrayal of Oscar Wilde, Vincent Price tells of an early friendship with a younger boy and the awesome sweet pain of discovering, after a blithely obtuse parting, left in a railway car with the other boy's tears on his face and his kiss on his lips, that that had been love. Not a new feeling, caused by the parting, but the old one, revealed and interpreted by it.

${ }^{3}$ Descartes (and Freud, see below) are of course more subtle than my impressionistic account, but I do not think the subtlety affects my argument.
} 


\section{4 / GENDER AND (INTER)SUBJECTIVITY}

a consideration of the three ways in which our emotions and our knowledge of them can change.

\section{Becoming Angry}

The first sort of change is this: as women come to believe that it is neither natural nor inevitable that they stay at home and experience most of the world at one remove, that their sacrifices of goals and dreams and freedom were not in their real interest, they often become angry. Their lives could be a whole lot better than they are, and someone or something is to blame. The object of their blame and anger varies from the closeness and specificity of a husband to the political generality of society and social institutions.

We can question whether the anger these women feel is justifiable, and if so what its appropriate objects are. We can even question whether emotions are the sorts of things that can be justifiable or appropriate at all. However, the claim that people do become angry in this way appears uncontroversial.

The traditional picture of mind can account for becoming angry by explaining how changes in leaves in or beneath the stream engender new ones. To give such an account strains only my metaphor, but the account itself is strained when we turn to the second and third sorts of changes.

\section{Discovering That One Has Been Angry}

To begin with, we need a clear and detailed account of what is meant to have happened when someone is said to have discovered that she was angry. Alice belongs to a consciousness-raising group. When she first joined she was generally satisfied with her life. But she became gradually more aware of those times when she felt depressed, or pressured and harried, as though her time were not her own. However, she didn't believe her time ought to be her own, so in addition, she felt guilty. She would sometimes snap at her husband or children, or cry without quite knowing why, and then put her "moodiness" down to various causes, such as her neuroses or her menstrual cycle. She didn't think she had any reason to feel this way; she never took the bad feelings as justified or reasonable; she didn't identify with them; they came over her and needed to be overcome.

Within the group Alice's feelings are responded to differently. She is encouraged to acknowledge and to express them in a safe environment, in which she has little fear that her feelings will disappoint, disillusion, hurt, or anger those around her. Furthermore, there is a growing shared sense, not only of the reality, but of the legitimacy and, finally, the justifiability of Alice's feelings.

We must distinguish here among the reality, the legitimacy, and the justifiability of feelings. One can acknowledge the reality of an emotion while believing that it is in some way illegitimate. And to acknowledge that one's feelings are legitimate-since to be justifiable. unfounded, needle It is likely that the reality of her $d$ This denial amoul she is unable to $f_{c}$ for those other fee anger as legitimat

If Alice comes that she had been in fact, have denie that a denial that justified in being focusing on one's

If we accept th knowing it she $h_{i}$ the submerged le along, to make $\mathrm{A}$ of course, actual manipulated Alic is now clearly ar so? It's yesterda? hands on that.

Not only woul anger, but it may discovered. Wha anger is an inabi] perspective. At 1 synthesizing the ]

One is the myt us that they are wholly personal, tend to be diffus event, mean any weather, or a pier right about the a: feels unfair and $\mathrm{r}$ myth makes us fi A second feat our own insecur: that someone $(0$ : 
ons and our knowledge of

, believe that it is neither ience most of the world at and freedom were not in zould be a whole lot better The object of their blame a husband to the political

el is justifiable, and if so whether emotions are the all. However, the claim roversial.

ning angry by explaining $r$ new ones. To give such self is strained when we

Jf what is meant to have at she was angry. Alice joined she was generally rare of those times when $r$ time were not her own. 1, so in addition, she felt ren, or cry without quite ious causes, such as her I any reason to feel this able; she didn't identify $\therefore$

ferently. She is encourronment, in which she $\mathrm{n}$, hurt, or anger those not only of the reality, $\therefore$ 's feelings.

$z y$, and the justifiability on while believing that lat one's feelings are legitimate-sincere, not self-deceptive-is not necessarily to take those feelings to be justifiable. They may, no matter how deeply or fully felt, be irrational, unfounded, needlessly self- or other-destructive.

It is likely that the other women in the group will urge Alice to acknowledge the reality of her depression and guilt, but to deny the legitimacy of those feelings. This denial amounts to the claim that she is in some way feeling something that she is unable to face. The guilt and the depression are a response to and a cover for those other feelings, notably feelings of anger. Alice is urged to recognize her anger as legitimate and justifiable in this situation.

If Alice comes to this recognition, we may describe her as having discovered that she had been angry, though she hadn't previously recognized it. She would, in fact, have denied it if she were asked: "Why should I be angry?" It is significant that a denial that one is angry often takes the form of a denial that one would be justified in being angry. Thus one's discovery of anger can often occur not from focusing on one's feelings but from a political redescription of one's situation.

If we accept the plausibility of the notion that Alice can discover that without knowing it she had been angry, we may initially be tempted by the analogy of the submerged leaves. We may think that the anger must have been there all along, to make Alice's anger not just a politically helpful fiction. But we cannot, of course, actually produce her past anger to satisfy the critic who says we manipulated Alice into a suspiciously revisionist rewriting of history. Even if she is now clearly and straightforwardly angry, couldn't it be that she just became so? It's yesterday's anger we need here, and there seems no way of laying our hands on that.

Not only would no newly discovered leaf provide conclusive evidence of past anger, but it may be that there is no particular item in our mental life left to be discovered. What is primarily keeping us as women from acknowledging our anger is an inability to interpret our feelings and behavior in the proper political perspective. At least three different aspects of sexist ideology help prevent our synthesizing the pieces and naming the puzzle of our feelings.

One is the myth about the emotions, women's emotions in particular, that tells us that they are irrational or nonrational storms. They sweep over us and are wholly personal, quite possibly hormonal. The emotions that fit with this picture tend to be diffuse, like moods, or episodic and undirected. They don't, in any event, mean anything. Thus we have outbursts of anger aimed at children, the weather, or a piece of balky machinery. We often feel there's something not quite right about the anger; it's out of proportion, and, especially if aimed at children, feels unfair and wrong. Instead of encouraging us to interpret these outbursts, the myth makes us feel guilty for having succumbed.

A second feature of our lives that keeps us from putting the pieces together is our own insecurity. The central cases of anger are judgmental, a way of feeling that someone (or some group) has acted badly. In order to be straightforwardly 
angry, one standardly has to trust one's own reactions and take oneself to be in a position to judge. ${ }^{4}$ That can be very hard to do from a position of dependency, where one's welfare and happiness depend on pleasing others. Even outside of marriage women are expected to be uncritical and unchallenging, and it can be very threatening to step back from this network of expectations.

A third thing keeping us from seeing ourselves as angry is the picture we are likely to have of what the good life for a woman consists in. Anger is "objecthungry": if there is no one and nothing to be angry at, it will be harder to see oneself as really angry. If the life one has is just what one has expected would be most satisfying and fulfilling, and if one's sacrifices are seen merely as the transcending of childish dreams, then it will be hard to find anyone or anything to be properly angry at. It is similarly hard to be properly angry if one thinks one's life as a woman is "natural," ordained by biology. The limitations that flow socially from one's being a woman are seen as on a par with those that flow from physical or biological factors. ${ }^{5}$

It is, of course, possible to be irrationally angry at a situation that is ane thinks it should be or that no one is to blame for. We may find ourselves angry and wonder why; it seems so uncalled for and childish. But the difference between someone who is irrationally angry and someone who is not may not be a difference in what they feel so much as a difference in what sorts of feelings, under what sorts of circumstances, they are ready to take as anger. When we judge that people are right to deny the name of anger to their irrational reactions, we are often judging that their situation, unlike Alice's, does not really call for anger.

But those who do take those reactions as anger may not be mistaken. Having noted this point, we are faced with the complex relationship between being angry and taking ourselves to be. If we take ourselves to be angry, whether justifiably or not, our anger changes. We begin to see things differently, as it were through the anger; it colors our world, both inner and outer. We find, because we are looking for them, more reasons for our anger and more feelings

${ }^{4}$ Not, of course, that all anger is so explicitly judgmental or sees itself so clearly in the right. But although people can be angry while knowing they have no good reason to be, those who find it difficult to acknowledge anger are often helped by coming to see that it would be justifiable for them to feel it.

5Freud is often mistakenly seen as holding this view ("anatomy is destiny"), but his actual view, although more subtle, serves the same ends. He is well aware both of the social origin of the norms of femininity and of their mutilating effects, but it is perhaps the clearest evidence of the deep pessimism of his later life that he saw the alternative to such socialization (and to the corresponding socialization of men) as barbarism: the situation may be awful, but there is nothing to blame but civilization itself, a barely more appropriate object of anger than biology. we can take as anger, whict have noticed. Our feelings, $\mathrm{j}$ i the fact of our anger. ${ }^{6}$

Or we can resist this. We $c$ uninterpreted or search for son Thus, to discover that we have we are never simply mistak confused, but we cannot be " $\mathrm{r}$ our emotions, those emotions

We can recognize this dif: others see them and go on tc If I fail to interpret my feelin odd and erratic, and therefore of someone who was angry s name the emotions have to do is connected with a comple: themselves in the same way :

In light of these observatic view that we are each the ult: less as a fact of epistemolog. care about in our interpretati in part because of the emoti workings of an ideology: ma unchangeable fact. We think specifiable independently of

The individualism that $\mathrm{ch}$ historically nonaccidental. ] underlying liberal economic place freely with already fo psychologically detachable We are both the legal and eI cal predicates (such as is : significant patterns, ways o particular social needs, it $v$

\footnotetext{
${ }^{6}$ For a similar view in the cc Rationality of Emotions," Dic Emotions, ed. Amelie Ockenst nia Press, 1980).

${ }^{7}$ Stuart Hampshire, "Since Essays (Princeton, N.J.: Prin owes much to his, although hi
} 


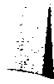

Anger and the Politics of Naming

$s$ and take oneself to be in 1 a position of dependency, ng others. Even outside of challenging, and it can be ectations.

angry is the picture we are nsists in. Anger is "objectat, it will be harder to see at one has expected would ces are seen merely as the to find anyone or anything operly angry if one thinks $y$. The limitations that flow ir with those that flow from

it a situation that is as one z may find ourselves angry lildish. But the difference neone who is not may not ifference in what sorts of re ready to take as anger. e name of anger to their : situation, unlike Alice's,

ly not be mistaken. Having elationship between being :lves to be angry, whether see things differently, as inner and outer. We find, ur anger and more feelings

or sees itself so clearly in the zy have no good reason to be, relped by coming to see that it

'anatomy is destiny"), but his $\mathrm{He}$ is well aware both of the ating effects, but it is perhaps : that he saw the alternative to $\mathrm{n}$ of men) as barbarism: the vilization itself, a barely more we can take as anger, which we may before have labeled differently or not have noticed. Our feelings, judgments, and behavior become organized around the fact of our anger. ${ }^{6}$

Or we can resist this. We can either let our feelings and our behavior remain uninterpreted or search for some other meaning. We can be mistaken in doing this. Thus, to discover that we have been angry is to correct an earlier interpretation. But we are never simply mistaken, the way others can be about us. We can be confused, but we cannot be "merely or wholly wrong." "If we are confused about our emotions, those emotions themselves are confused.

We can recognize this difference between how I see my emotions and how others see them and go on to ask why this difference exists. One point is clear. If I fail to interpret my feelings and behavior as anger, they are likely to be both odd and erratic, and therefore less coherent and predictable than you would expect of someone who was angry straightforwardly. The patterns we pick out when we name the emotions have to do with the needs of social life: seeing people as angry is connected with a complex set of expectations of them, and their not seeing themselves in the same way affects the validity of those expectations.

In light of these observations, the theory of privileged access (the philosophical view that we are each the ultimate authority about our own emotions) can be seen less as a fact of epistemology than as a piece of social theory-a clue to what we care about in our interpretations of people. That we are inclined not to notice this, in part because of the emotions-as-inner-states picture of mind, is typical of the workings of an ideology: matters of political choice come to seem to be matters of unchangeable fact. We think that emotions just are particular states of individuals, specifiable independently of social context.

The individualism that characterizes this view of the mind and the emotions is historically nonaccidental. It fits with the essentially atomistic view of persons underlying liberal economic and political structures, of agents entering the marketplace freely with already formed motivations and desires. We treat each other as psychologically detachable units and regard ourselves as the owners of ourselves. We are both the legal and epistemic authorities. Since the view about psychological predicates (such as 'is angry') that I am urging is that they pick out socially significant patterns, ways of organizing feeling and behavior in accordance with particular social needs, it would be expected that in a society like ours primacy

\footnotetext{
${ }^{6}$ For a similar view in the context of a different sort of theory, see Ronald deSousa, "The Rationality of Emotions," Dialogue: Canadian Philosophical Review, and in Explaining Emotions, ed. Amelie Ockensberg Rorty (Berkeley and Los Angeles: University of California Press, 1980).

'Stuart Hampshire, "Sincerity and Singlemindedness," Freedom of Mind and Other Essays (Princeton, N.J.: Princeton University Press, 1971), p. 237. My discussion here owes much to his, although his does not extend beyond the limits of the individual.
} 


\section{$28 /$ GENDER AND (INTER)SUBJECTIVITY}

would be given to first-person perception. We care most about our own view of ourselves since we are the ones who are allowed to determine how we are to be taken as feeling: privileged access functions as a sort of property right.

I may think, and you may disagree, that you are angry with me, or in love with me, but are afraid to admit it even to yourself. That may seem to me to be the clearest sense to be made of the confusing ways you feel and the strange ways you act. And I may, insofar as I can, treat you as someone who is angry at (or in love with) me, thus making our relationship to a certain extent what it would be if you acknowledged these things. But are you really angry or in love? There may be no answer to this. What you are is confused and conflicted; you haven't settled yet on a clear way to be. There is no reason to think that under the muddle is a clear fact, a leaf beneath the silt.

Now why do you get to do the settling? What is wrong with my taking you to be some way you don't take yourself? What I want to suggest is not that I am any less likely than you to be right, but that I haven't got the right: I am an intruder, failing to respect your privileged access to yourself. ${ }^{8}$ It is certainly true that we take people to have these sorts of rights to their own(ed) feelings; we may think they are wrong, but we do not normally have the right to treat them according to our conception of them rather than their own. People can confer on others the right to interpret their feelings, or can lose their right to do it themselves, by being declared insane, which means, among other things, that one's own view of oneself is not the one the rest of us have to respect.

Less extremely, this right is unequally distributed. Adults, for example, often tell children what they are and are not feeling, and what those feelings mean ("You're just overtired"). And the interpretation of women's feelings and behavior is often appropriated by others, by husbands or lovers, or by various psychological "experts." Autonomy in this regard is less an individual achievement than a socially recognized right, and, as such, people with social power tend to have more of it.

But, as with other sorts of property rights, we can recognize and seek to change an inequality of distribution while working ultimately for more fundamental changes. We can, that is, explore the possibility of allowing our emotions to be fully and openly social constructions, rather than needing, as we do now, to acquire and keep to ourselves the final authority about them.

Consider, for example, the interactions of feeling and perception in a consciousness-raising group. A frequently remarked feature of such groups is that each woman's ability to recognize and change her situation depends on the others' doing the same. Part of why this is important lies in how it is that one is being seen and responded to. Although it is true that women are taught to be overly

${ }^{8}$ For an interesting discussion of the nature and importance of our consideration of other people's self-conceptions, see Elizabeth V. Spelman, "Treating Persons as Persons," Ethics 88 (1978): 150-61.

\footnotetext{
${ }^{10} \mathrm{R}$. D.

Books, 1S
}

${ }^{9}$ For ac 
sare most about our own view of $\mathrm{d}$ to determine how we are to be sort of property right.

re angry with me, or in love with That may seem to me to be the $s$ you feel and the strange ways ; someone who is angry at (or in I certain extent what it would be really angry or in love? There Ised and conflicted; you haven't in to think that under the muddle

is wrong with my taking you to vant to suggest is not that I am haven't got the right: I am an to yourself. ${ }^{8}$ It is certainly true s to their own(ed) feelings; we lly have the right to treat them heir own. People can confer on se their right to do it themselves, her things, that one's own view sct.

ted. Adults, for example, often and what those feelings mean women's feelings and behavior srs, or by various psychological ndividual achievement than a ith social power tend to have

1 recognize and seek to change nately for more fundamental $f$ allowing our emotions to be I needing, as we do now, to sut them.

and perception in a conscious: of such groups is that each ation depends on the others' in how it is that one is being men are taught to be overly

nce of our consideration of other ating Persons as Persons," Ethics dependent on our reflections in the eyes of others, it is a serious mistake to conclude from this that we ought not to care about or attend to how others see us. We need to be selective about whose views we care about and why and about how people's views are distorted and manipulative. But to attempt to cease to care is to adopt an asocial, individualistic picture of people that it has been one of the important goals of feminism to deny. The serious question posed by the experience of such groups is how to characterize the connections between how we really are and how we are seen. This question is at once normative and descriptive.

There are many such connections apparent in the workings of a consciousnessraising group: that between being listened to and taken seriously and the development of self-respect, or between being genuinely sympathetic and having one's expressions of sympathy acknowledged. ${ }^{9}$ Here I want to focus on the relevance of these considerations to the discovery of anger.

For example, when Alice finds herself snapping at the children or complaining to her husband, she is apt to feel like some sort of monster for not being made happy by her life. The crystallization of her feelings will be impeded in part by her unwillingness to face the sort of person she thinks she would be were she really angry. But in the group, women she has grown to know and to like confess to similar feelings. As the other women realize that they are angry, Alice's certainty that they are not monsters will make it easier for her to accept that she is angry too. Shifting notions of normality function like this: as it becomes more expected that children will be angry at their parents, it becomes easier for people to interpret a lot of darkly baffling feeling and seemingly perverse behavior.

Conversely, R. D. Laing draws our attention to the ways in which family members can invalidate each other's experiences. ${ }^{10} \mathrm{~A}$ powerful family mythology about what someone ought to be feeling can override otherwise much more plausible readings, warping her interpretations, leading her to focus on or to ignore certain aspects of her feeling and behavior. One reason this can happen is that feelings don't bear their meanings on their faces: we need to learn socially what they add up to. We interpret our reactions and our behavior in the light of this family mythology, so when, as happens in a consciousness-raising group, it is challenged and undermined, we are apt to see our lives and our emotions differently.

The bestowing or the withholding of a name can be personally and politically explosive. To see that some state of affairs counts as oppression or exploitation, or that one's own feelings count as dissatisfaction or anger is already to change the nature of that situation or those feelings.

\footnotetext{
${ }^{9}$ For a discussion of this and related issues, see my "On Sympathy."

${ }^{10} \mathrm{R}$. D. Laing and Aron Esterson, Sanity, Madness and the Family (New York: Basic Books, 1965).
} 
$30 /$ GENDER AND (INTER)SUBJECTIVITY

\section{Changing What Counts as Being Angry}

We inherited from Freud, whether he intended it or not, a way of accounting for the discovery of anger. There is supposed to be a particular state people are in when they are angry, a state that can be either conscious or unconscious. Unconscious anger is the same sort of thing as conscious anger, just as a submerged leaf is the same sort of thing as an unsubmerged leaf: it is supposed to be obvious that whatever is repressed is anger. What Freud is supposed to have discovered is that emotions, intentions, beliefs are not necessarily conscious; precisely those things can be hidden from us.

To put the matter this way is to represent Freud as holding a sophisticated version of the view of emotions as inner states. Most of the time this is how he represents himself. By demonstrating that the processes that characterize our conscious lives also appear in unconscious forms, Freud claims to be taking the sort of insight into feeling and behavior we receive from poets, novelists, playwrights, and both extending it and making it scientific (ultimately neurophysiological).

Freud defines "psychical acts" as those that "have a sense." In showing that, for example, parapraxes, dreams, and neuroses have a sense, that is, "meaning, intention, purpose and position in a continuous psychical context," rather than arising "immediately from somatic, organic and material influences," he takes himself to be making "a quite considerable extension to the world of psychical phenomena and [to] have won for psychology phenomena which were not reckoned earlier as belonging to it." 11

This description of Freud's achievement is, I think, apt, but it admits of two divergent interpretations, one that fits with the emotions-as-inner-states view and one that fits with my alternative. Under the first interpretation there is a mechanism of the mind, a set of basic processes, that produce all the contents of consciousness and all intentional behavior. On this view Freud takes himself to have discovered convincing evidence for the claim that many pieces of behavior we had been taking as caused by a distinct sort of physical mechanism are in fact caused by an underlying and hidden extension of the mechanism of the mind and by underlying states essentially like their conscious counterparts (which cause pieces of straightforwardly intentional behavior). It is in terms of this (as yet only programmatically specified) mechanism of the mind that unconscious intentions, motivations, and beliefs are identified. Psychoanalysis uncovers evidence for the causal structure of this mechanism, and thus for the unconscious states and processes that can be recognized by their roles in it. This is a natural way of

\footnotetext{
${ }^{1}$ Sigmund Freud, Introductory Lectures on Psychoanalysis, eds. James Strachey and Angela Richards, Pelican Freud Library, vol. I (Harmondsworth, Middlesex: Penguin Books, 1976), pp. 87-88.
}

taking what Freud mean a continuous psychical c

But there is another, I on nor supports the viev marshals as evidence ( $\mathrm{p} \varepsilon$ about them, the behavio. constituting a meaningf the postulation of ghostl:

Consider the followir say, my shouting at anc me. We also have a num me and that he could har

The traditional pictur is the feeling (one of th about) his behavior, and case to a case of parapr supposed to see the cau the central, apparently n the existence of my $\mathrm{r} \epsilon$ repressed, a complicatic causing my otherwise in

The problem here is conscious and the uncr feelings, beliefs, and be Simply, there is no justit most of the time there there are many, possibly characteristic of anger crushing to nothing at a is some identifiable, pe the feelings.

What makes the who a whole similar, in way: is not inferred similarity is no particular state, cr itself settle the questio question, we need to le stances, and we need to I have argued that

\footnotetext{
${ }^{12}$ For a criticism of thi: J. L. Austin, "Other Mind (Oxford: Oxford Universil
} 
a way of accounting zular state people are ious or unconscious. anger, just as a subzaf: it is supposed to is supposed to have cessarily conscious;

ding a sophisticated time this is how he lat characterize our slaims to be taking im poets, novelists, imately neurophysi-

$\therefore$ "In showing that, , that is, "meaning, intext," rather than 7uences," he takes world of psychical ich were not reck-

It it admits of two ler-states view and zre is a mechanism $s$ of consciousness o have discovered vior we had been in fact caused by he mind and by 'hich cause pieces this (as yet only scious intentions, , evidence for the cious states and a natural way of

mes Strachey and iddlesex: Penguin taking what Freud means when he says that to have sense is to have a "place in a continuous psychical context."

But there is another, I think more plausible, interpretation, which neither relies on nor supports the view of emotions as inner states. We could take what Freud marshals as evidence (parapraxes and dreams and what people spontaneously say about them, the behavior of children, neurotic symptoms) as itself significant, as constituting a meaningful pattern of mental occurrences and behavior, without the postulation of ghostly entities and a ghostly mechanism holding it all together.

Consider the following picture: we have some pieces of intentional behavior, say, my shouting at and then walking out on someone I take to have wronged me. We also have a number of relevant beliefs (in particular, that he has wronged me and that he could have avoided it) and some conscious feelings.

The traditional picture tells us that these fit together causally. The focal point is the feeling (one of the feelings?), which is the anger, caused by (my beliefs about) his behavior, and in turn causing mine. ${ }^{12}$ When we turn from the conscious case to a case of parapraxis or a piece of neurotic behavior or a dream, we are supposed to see the causal chain clearly enough for us to infer the existence of the central, apparently missing piece: the emotion itself. So, for example, we infer the existence of my repressed anger as caused by my belief (perhaps itself repressed, a complication) that I have been somehow avoidably wronged and as causing my otherwise inexplicable behavior or symptoms.

The problem here is not with the convincingness of the analogy between the conscious and the unconscious cases but with the initial picture of how the feelings, beliefs, and behavior fit together when the whole affair is conscious. Simply, there is no justification for identifying the anger with the feeling, because most of the time there is no one feeling (sometimes there are none; sometimes there are many, possibly conflicting), and there is most certainly no sort of feeling characteristic of anger (it can feel like almost anything, from exhilarating to crushing to nothing at all). Nor is there any real reason to infer that behind it all is some identifiable, peculiar state that is the anger and causes the behavior and the feelings.

What makes the whole affair a case of someone's being angry is how it is as a whole similar, in ways we particularly care about, to other cases. The similarity is not inferred similarity of mechanism but conferred similarity of meaning. There is no particular state, conscious or unconscious, mental or physical, that will by itself settle the question of whether someone is angry. In order to settle this question, we need to learn more about the person's behavior, feelings, circumstances, and we need to know how to interpret what we learn.

I have argued that by extending the range of phenomena we can see as

${ }^{12}$ For a criticism of this point similar to mine but from a slightly different angle, see J. L. Austin, "Other Minds," Philosophical Papers, eds. J. O. Urmson and G. J. Warnock (Oxford: Oxford University Press, 1961), esp. p. 77. 
meaningful Freud has given us an alternative way of thinking about our psychic lives. We can speak of unconscious motivations, emotions, and so on, just as we speak of conscious ones: as ways of interpreting feelings and behavior that are complex and otherwise inchoate (despite whatever causal links science may uncover). Thus Freud has led us to expand the range of cases that count as cases of anger, not just in the sense that we can now point to some we couldn't have pointed to before (as biologists increased our repertoire of organisms by discovering the existence of many invisible to the naked eye), but by changing our notions of what it is to be angry. Although unconscious anger is anger in just the same sense as conscious anger is, to see that this is so is not so much to uncover some new datum as to learn to see the old data differently. Freud's insight leads us away from focusing on the nature of the emotion itself as some identifiable thing, toward looking at the meaning of feelings and behavior seen in historical and interpersonal context.

\section{Speculations on the Emotions, Politics, and the Power of Naming}

I have suggested that to account for the phenomenon of discovering that someone has been angry it is necessary to change the sorts of patterned situations that are seen as significant. Even people not otherwise sympathetic to psychoanalysis are now inclined to identify emotions by their place in an individual's history, not just by how they feel. What I want to consider now is the possibility that we can come to name and classify emotions differently for reasons that are not just individually historical-a sort of "political psychoanalysis."

One thing that led us to see unconscious anger as genuine anger was that we saw someone's feelings and behavior hanging together coherently and pointing in a certain direction. And we came to see this by seeing a stretch of her life as a whole: the judgment that she was angry embodied not just a claim about her present state but facts about the past and expectations about the future. We can come to a similar realization about a group-that it has a history, an organized present, a probable future. And coming to see this can lead us to think differently about the feelings and behavior of individuals of that group.

Consider women and anger. Part of what makes it true that a woman is angry today is that her vague and unfocused feelings are apt to crystallize in the future as she becomes clearer about the nature of sexism and its role in her life. We identify her feelings and behavior today as straightforwardly angry partly with reference to this possible future, their natural one. Calling this future course "natural" means here that the political beliefs she comes to have are true, and her not having had them previously can be explained as part of the distorting effect of a false ideology. The requirement that the future course be in this sense natural supports one of the central points of this essay - that substantive political considerations are prior emotions. ${ }^{13}$

But this future cours of course, having femi (introspectively) feel, $\mathrm{t}$ someone who felt like not previously have bee was then neither the lik that would have made feelings and behavior a today is the product of grow.

We can look back a us to explain more of $v$ been correct to say it given a meaning to wt future for it within the can see confused and c a state that would bec false beliefs, and inter: behavior of women in in their lifetime anyw anything; they didn't $c$ significance such feeli

In the light of this , belligerence of the cri tion that I have been the nature-of anger, would be were they si act in ways we migh with collective politic

We can thus make "you just feel what yc is no accident that su damper on the sorts of the sort of discovery you can really know you never will.

Another, more inte are criticized is that 1

\footnotetext{
${ }^{13}$ This point about na scope of the paper and,
} 
inking about our psychic ns, and so on, just as we gs and behavior that are uusal links science may cases that count as cases nt to some we couldn't jertoire of organisms by :d eye), but by changing ous anger is anger in just is so is not so much to fferently. Freud's insight itself as some identifiable havior seen in historical

\section{er of Naming}

non of discovering that ts of patterned situations mpathetic to psychoanal$\mathrm{n}$ an individual's history, is the possibility that we reasons that are not just is."

nuine anger was that we coherently and pointing ig a stretch of her life as tt just a claim about her ibout the future. We can ; a history, an organized ad us to think differently up.

le that a woman is angry , crystallize in the future I its role in her life. We vardly angry partly with thing this future course to have are true, and her $t$ of the distorting effect course be in this sense that substantive political considerations are prior to the correct identification, even to the identity, of the
emotions. $^{13}$

But this future course has become at all likely only quite recently. Although, of course, having feminism in the air has a great deal to do with how people (introspectively) feel, there is another, subtler difference. I want to suggest that someone who felt like a woman who is unstraightforwardly angry today would not previously have been considered to be, and would not have been, angry. There was then neither the likelihood of future crystallization nor any way of thinking that would have made it appropriate to gather together some odd jumble of feelings and behavior and call it "anger." The meaning that the jumble has for us today is the product of social change; it has acquired a way to organize itself and grow.

We can look back and say of someone that she was angry because it enables us to explain more of what was going on. But it doesn't follow that it would have been correct to say it of her then: what counts as anger has changed. We have given a meaning to what previously had none; it had none because there was no future for it within the social, political, and economic reality of earlier times. We can see confused and obscure anger today as anger by seeing it as embryonic, as a state that would become straightforward anger were certain social pressures, false beliefs, and internalized fears removed. But the corresponding feelings and behavior of women in the past were not leading anywhere, not for most women in their lifetime anyway, and so there was no reason to see them as meaning anything; they didn't count as anger because they lacked even the potential social significance such feelings and behavior have today.

In the light of this claim I think we can make sense of the defensiveness and belligerence of the critics of consciousness-raising groups. If there is the connection that I have been suggesting between politics and the discovery-and even the nature-of anger, then emotions become much more threatening than they would be were they simply inner states. Anger could on that view lead people to act in ways we might reasonably fear, but it wouldn't be intimately bound up with collective political action.

We can thus make sense of the current craze for psychological individualism: "you just feel what you feel; get in touch with what's really there inside you." It is no accident that such a view is flourishing. It functions as a reaction to and a damper on the sorts of personal and political changes central to feminism, making the sort of discovery of anger I have been discussing impossible. As long as only you can really know what's going on in your own head, the odds are fairly high you never will.

Another, more intellectually serious way in which consciousness-raising groups are criticized is that they are seen as manipulative of the feelings of the women

\footnotetext{
${ }^{13}$ This point about naturalness needs both clarification and defense. Both are beyond the scope of the paper and, at the moment, of its author.
} 


\section{4 / GENDER AND (INTER)SUBJECTIVITY}

in them, that people come to feel (or to think they feel) what the group deems proper. If I am right and there actually is something like this going on, it is important to acknowledge, define, and ultimately defend it, rather than simply accept the terms in which the criticism is couched and try to refute it. Some groups undoubtedly are manipulative in a way any disinterested person would recognize and deplore-I'n not concerned with then here. But the idea that there is a context in which you can simply "get in touch with your feelings," free from the influence of other people or of political concerns, is a dangerous myth.

The idea that I am the way I am no matter what anyone else thinks is not politically neutral. To take this position is to stifle the possibility of particular sorts of political change. But it's also to blind ourselves to the truth that we are in many deep and important ways what others take or at least allow us to be. Whether or not we are really angry, beneath the confusion and the pain, depends in part on the particular social processes, which will give or fail to give our feelings the possibility of definition.

The structure that consciousness-raising groups provide for the interpretation of feelings and behavior is overtly political; it should be immediately obvious that one is presented with a particular way of making sense of one's experience, a way intimately linked with certian controversial political views. Consciousnessraising groups are not, however, unique in this respect. What they are is unusually honest: the political framework is explicit (though often vague) and openly argued for. The alternative is not "a clear space in which to get your head together" but a hidden political framework that pretends not to be one and hence is spared the bother (and the risk) of argument.

\section{Apologia}

In this paper I have attempted to identify a source of discomfort, a project that makes complete sense only to those whose discomfort it is. I have gone on to suggest how we might construct an alternative framework, a project that is likely to seem simply perverse to someone committed to the old one.

We experience this discomfort as feminists when we realize that our experiences are leading us to think differently about people and human relationships, while the only concepts available to think with are suited to forms of social organization shown to be outmoded by those very experiences. Forms of practice such as consciousness-raising groups can lead us to a fundamental revision of the conceptual structures in terms of which we name our experiences. We can, in particular, question the underlying individualism of the traditional picture of mind.

It would be satisfying to think I could marshal arguments sufficiently cogent to convince any (rational) reader: philosophers are supposed to aim at that, not just preach to the converted. But there's another kind of philosophical task: to bring to light, clarify, and explain the nature and sources of dimly perceived 
contradictions in or between our concepts and our social practice. Such contradictions may have been there all along, but their presence causes particular trouble when social practice is changing. One doesn't choose here between explaining the world and changing it; rather one explains (and perhaps facilitates) the changes by changing the explanations. 
